\title{
Is IPOs trading enhanced with the advent of automated trading system? A look at the efficient market hypothesis
}

\author{
P. M. C. Thilakarathne ${ }^{1,2}$, Alex Augustus Ambore Bruce ${ }^{1,2}$ \\ ${ }^{1}$ Department of Accountancy, Faulty of Commerce \& Management Studies, University of Kelaniya, Sri Lanka \\ ${ }^{2}$ Department of Business Administration, Gombe State University, Nigeria
}

Email address:

lal@kln.ac.lk (P. M. C. Thilakerathne), brucealex46@gmail.com (A. A. A. Bruce)

\section{To cite this article:}

P. M. C. Thilakarathne, Alex Augustus Ambore Bruce. Is IPOs Trading Enhanced with the Advent of Automated Trading System? A Look at the Efficient Market Hypothesis. International Journal of Business and Economics Research. Vol. 3, No. 2, 2014, pp. 72-81.

doi: $10.11648 /$ j.ijber.20140302.14

\begin{abstract}
We examine and model the performance of Initial Public Offerings (IPOs) with the advent of the Automated Trading System (ATS) on the Efficient Market Hypothesis (EMH) of Fama (1970) and observe that the system of price determination and encoding such information to existing and potential investors for IPOs has significantly improved with related efficiency as most of the IPOs issued during the period after the introduction of the ATS have significantly attracted more investor demand and commendable pricing mechanism as a result of easy and quick access to information sharing. This could mean that information asymmetry has drastically reduced since they are electronically generated to produce the stock prices within a very limited period of time. But until now, prices of IPOs in most cases do not fully reflect available information as the EMH suggests and does not fulfil the Random Walk Hypothesis (Kendall, 1953, RWH) as a requirement for weak form of market efficiency. However, despite the ATS's immense contributions, the rate of price swings and inability to fully reflect available information still remains an apparition to the market participants so that prices are either overpriced or underpriced. We use the stability, stationary, and normality diagnostic tests together with the EGARCH and TGARCH to define the trend of the prices. The result is not consistent with the Efficient Market Hypothesis of Fama (1970). Data on each IPO daily prices were obtained from the trading statistics of Colombo Stock Exchange (CSE) consisting of 231 IPO stocks traded between the years 2000 to 2012 consisting of 35,979 monthly observations; these prices are those of IPOs trading after the introduction of the ATS in 1997. The outcome clearly shows that the prices are not normally distributed and are significantly auto-correlated. This result does not support the RWH to satisfy for the weak market efficiency.
\end{abstract}

Keywords: Initial Public Offering, Automatic Trading System, Efficient Market Hypothesis, Random Walk Theory, Colombo Stock Exchange, Stock Demand, Information Asymmetry and Stock Price

\section{Introduction}

The Efficient Market Hypothesis of Fama (1970, EMH) states that a stock market is said to be efficient if all stocks price "fully reflect" information about the issuer and the market trend, and capable of being independent of each other fulfilling the random walk hypothesis of Kendall (1953, RWH $)^{1}$ which means that if a firm intends to float Initial Public Offerings (IPOs) in the market and decide to offer at 35 Sri Lankan Rupees (Rs.35); this price basically should be a full reflection of the true value of the firm and the true value

\footnotetext{
1 This means that the stock price fluctuations are independent of each other and have the same probability distribution, but that over a period of time, prices maintain an upward trend. In short, random walk says that stocks take a random and unpredictable path.
}

of information regarding the market at the time of the floating and that the future returns should not be determined by past prices. Of course this hypothesis may seem unrealistic even though Fama concluded that the U.S. stock market, from his empirical results, is an efficient market, which though cannot be disputed yet the fact still remains that information value in itself cannot be thoroughly ascertained in whatever way we manipulate it. For the fact that capital market efficiency operates in two forms (i.e. external efficiency and internal efficiency), such conditions are hardly attainable in a world of imperfection (Machiraju, 2009). Likewise, competition between informed investors for stocks is most likely to push the prices up or down depending on the state of the mind of the investors and the future gains anticipated. This line of our believe is supported by Rubalcava (2013) who asserts that, the 
competitive process of detecting mispriced securities actually makes the market more efficient, that is, market prices reflecting their fundamentals; so that it appears that variation in techniques and acumen are not completely accounted for the efficient market hypothesis. In a similar postulation, Shiller (2002) asserts that theoretical models of efficient financial markets that represent everyone as rational optimizers can be no more than metaphors for the world around. However, there is a degree to which that could be done as the earlier studies of Fama (1965, 1968, 1970), Lintner (1965), Niederhoffer and Osborne (1966), Jensen (1968, 1969), Scholes (1969), suppose strong, semi-strong and weak efficient markets, even though not still satisfactory because of the difficulty in ascertaining mispricing when there is actual competition. Yet we feel, we can skew our minds to a proportional-level satisfying model that can in some wise explain the situation in the emerging market of Sri Lanka. It is in the light of this that we use the Random Walk Hypothesis (RWH) as a necessary ingredient for the EMH to assess the efficiency of the Colombo Stock Exchange (CSE) in terms of weak, the semi-strong or strong with adaption of the automated trading system.

Information dissemination is always a problem in every stock market because of the numerous divergent views on the values of the firms trading in the markets. In most cases before the advent of the computer Automated Trading System (hereafter, ATS) on the stocks markets, information sharing was much weak and highly skewed so that while some arms of the market are almost fully informed, the other part is completely uninformed. Probably information sharing was hindered because they were manually transmitted and so some issuers and other market participants may choose to hide some information to create frenzy. These practices are believed to be products of issuers, underwriters and even corporate investors who sometimes release good news to create bubble or bad news to create crash and otherwise. We observe that in most cases, reaction to good news is always slow than reaction to bad news. This is mostly the reason why firms try at all times to keep their heads above the waters even if it will cost them to circulate misinformation as long as it will increase their value. So full information reflection in IPO prices may be relative and so may not be always true. This is why Lo (2007) give explanatory model in line with what naturally happen in the stock market, that in an evolutionary context, it is normal for mispricing to occur at some spaces within time since investors by trying to adapt to the changing and highly competitive new environment can make mistakes or act irrationally.

Although the current trend of the ATS posits a better and quicker information sharing and easy access so that firms financial information are displayed by experts before the IPO trading along-side the trends in the market; that investors have access to such information to also investigate the IPO price generated electronically by the system if it reflects the full information available, much deviations seem to exist in the IPO prices. It is in this light that we investigate the IPOs in the CSE whether their prices fully reflect the information required in the direction of the EMH and whether they are independent from each other- a satisfaction of the random walk hypothesis.

We however, observe that there is very high degree of volatility clustering such that shocks tend to persist over a very long period of time almost defying the mean reverting principles. It is also evident that the daily monthly price of IPO stocks tends to be dependent upon each other which mean that they are not randomly distributed and does not satisfy normal distribution test. The ATS has proved efficient in determining price of the IPO stocks but does not provide for fully reflected information pricing and as such information asymmetry is inevitable in the CSE even though the impact of good and bad news almost have equal congruent effects. Evidence abound that the ATS does not justify the efficiency of IPO stocks performance and so fails to satisfy the RWH as a weak form of market efficiency modelled in the EMH.

The rest of the paper flows in the following headings. The IPOs performance being a reason for adequacy in information sharing is reviewed in section 2. Section 3 discusses the operation of the ATS on the CSE and how prices are generated while section 4 presents the model specification and data. Section 5 comprises the results and discussions. Finally, section 6 concludes the paper.

\section{IPO Performance and Information Sharing}

Lowry et al (2010) observe that there is very high information asymmetry between the issuing firm and the market such that trading revolves the firm's uncertainty about the firm's aggregate demand which is then incorporated into the price. This reason suggests why the underwriters under-price the IPOs of firms with high information asymmetry (Rock, 1986). In a study of U.S IPO stocks, Bradley and Jordan (2002) and Lowry and Schwert (2004) show that the IPO initial returns are explained partly by the initial returns of previous IPOs of other firms. Between 1994 and 2001, the initial return of IPOs in the U.S. market was 22\% (Lowry et al., 2006). This is in line with further studies conducted by Loughran and Ritter (2002) and Lowry and Schwert (2004) that the initial returns are positively related to market-wide stock price increases before the IPO. Ritter (2003) further asserts that early pricing discussions focus on offer prices that are implied by the market values of publicly traded shares of comparable firms. Purnanandam and Swaminathan (2004) and Derrien (2005) observe that the offer prices reflect considerations of value relative to other publicly traded shares.

Bartram, et al (2012) in a study of volatility of U.S. stocks returns, discuss that a considerable literature emphasizes the impact of limits to arbitrage and shows that noise traders can influence stock prices and make stock returns more volatile. The literature does not make clear predictions on how the impact of noise trading should differ across countries. 
Opposing forces seem to be at work in this instance because of the varying contentions. They further assert that with more financial development, we expect trading to become cheaper and limits to arbitrage weaker so that stock prices would be closer to fundamental values. However, noise traders can trade more cheaply in countries with lower trading costs so that they could be more influential when trading is cheap. In this scenario, it is worthwhile to state that, a few noise traders steal the imbalances in the system to out-smart the market so the issue of market efficiency can only be achieved first via internal efficiency where transaction costs (commission, clearing fees and bid-ask spread) and taxes are low enough so as to distort the impact exerted by new information about value of the financial asset (Machiraju, 2009:23). In open economies, there is often a concern that foreign investors are noise traders, perhaps because they herd and make stock prices more volatile (Bartram, et al, 2012).

In corporate finance, it is generally assumed that there are more information asymmetries about growth opportunities than about assets in place (Myers \& Majluf, 1984). It is very obvious from most studies around the world that the IPO offer prices usually do not reflect the quantum of public information necessary to give good timing for the offer and pricing. This is because information that accumulates when financial markets are closed is reflected in prices after the market reopen; such that if information accumulates at a constant rate over calendar time, then the variance of returns over the period from the Friday close to the Monday close should be three times the variance from the Monday close to the Tuesday close. It is then paramount important to observe that volatility may seem high for IPO stocks because information about their true value may be locked-in to the parties especially the issuer and the underwriter.

Although Fama (1965) documents that information accumulates more slowly when the markets are closed than when they are open. Such that variances are higher following weekends and holidays than on other days, but not nearly by as much as would be expected if the news arrival rate were constant. Islam, Ali and Ahmad (2010) are of the opinion that IPOs are characterized by a great deal of uncertainty about their true value because of the scarcity of public information at the time of the initial offering. In such a noisy environment, judging the true value of a new issue is extremely difficult. Consequently, the initial return on an IPO (i.e., the difference between the first market price and the offer price) reveals significant information because it provides the first public indication that the market's average assessment of the IPO differs from that of the underwriter and the issuing firm. This implies that the initial market price should be able to signal the quality of the IPO. They further mention that the first market price may fail to reflect fully all available information because of the potentially fragmented market for IPOs. There is much probability to market fragmentation for IPOs when relating it to the power of information at close and open market periods. This is because earnings are not yet certain on IPOs at the point of their issues so volatility of the returns is unknown because Cornel (1978) observes that individual firms' stock returns volatility is high around earnings announcements. The firm's stock returns volatility is positively or negatively indicated by the open declaration of earnings; this is what accurately informs investors about the worth of the firm. Similarly, the release of macroeconomic news or periods of heavy trading by the central bank could escalate fixed income and foreign exchange volatilities which in-turn affect stocks returns volatility (Harvey \& Huang, 1991, 1992). Consistent to these assertions, Harris (1986), Baillie and Bollerslev (1991), Gerity and Mulherin (1992), Bollerslev and et al (1994) and several others indicate that volatility is typically much higher at the open and close ${ }^{2}$ of stock and foreign exchange trading than during the middle of the day. The issue size of IPOs is typically small and the underwriters, often facing excess demand, ration new issues to their regular clients, who constitute a small subset of potential investors (Benveniste \& Spindt, 1989; Benveniste \& Wilhelm, 1990; and Spatt \& Srivastava, 1991). Initial trading in the aftermarket serves to disseminate information about the value of IPOs to other investors. The firm is obligated to depend upon rich information from the market and the firm to determine its decisions on product/service pricing.

The London Chartered Institute of Bankers (1993) observe that business decisions depend majorly on information availability and processing such that the information need assist in:

(a) Providing right support for decision-making process and to provide the firm with competitive edge in its market place. Thus at every stage in the marketing process, whether it is trying to understand consumers or understand markets or establish levels of profitability for products or determine price, a variety of different types of information will be required;

(b) Throughout a marketing campaign, information will also be a key component of any monitoring and control system. Thus, in order to manage marketing, it is necessary to obtain and manage information.

This means that, the firm must operate an external data base for information collected from outside the firm which relates to the market within which it operates to use it to structure its internal data base in order to absorb risks where necessary. Information asymmetry is identified as one of the challenges facing emerging markets (Oluba; 2008, and Murray, 2008). Meaning that a thorough marketing research must be conducted to be sure of the information flows and how realistic they are for pricing and marketing the firm's products. ${ }^{3}$ it is notable to state that the market may overreact to both good and bad information in an environment characterized with information asymmetry. The decision support is therefore, the team of managers who use the

\footnotetext{
2 The increase in volatility at the open at least partly reflects information accumulated while the market was closed.

${ }^{3}$ Under the signalling theories (Allen and Faulhaber, 1989; Grinblatt and Hwang, 1989; and Welch, 1989) the initial market price provides a signal of the quality of the IPO.
} 
information available for decision-making.

Hence, in an IPO preparation, the firm is obligated to do this thorough investigation for the managers to be able to do the right pricing and underwriting option to go for. For instance studies conducted by Bradley and Jordan (2002) and Lowry and Schwert (2004) show that the IPO initial returns are explained partly by the initial returns of previous IPOs. This is in line with further studies conducted by Loughran and Ritter (2002) that the initial returns are positively related to market-wide stock price increases before the IPO.

This indicates that when investors believe business conditions are poor or average, they scrutinize firms with strong reports carefully so as to weed out bad firms that happen to have strong reports (Wang et al, 2010). Information for the past and present business is therefore required in great proportion by the issuing firm, issuing houses, underwriters and the investors alike.

This means that, the issuing firm can appropriately determine the IPOs par value while the issuing houses and underwriters can also determine the appropriate market price of the IPOs and finally the investing public will find the IPO price commensurate with the firm's market value. Without accurate information, investors made ill-advised decisions regarding bank stocks, enticed by a speculative market bubble which was allegedly partly fuelled by the banks through the practice of margin lending.

The firm's IPOs could be appropriately priced, underpriced or overpriced depending upon the information value available on the firm and its market/financial value. Although in most IPO cases, underpricing tends to take lead in most situations. Of course the firm can succeed in the market and sell its IPOs successfully and attractively if it has adequate information about the market and its variables.

Furthermore, information about the firm's operation becomes paramount to the underwriter as well as the investors because it help inform these players the position of the firm and the degree of certainty/uncertainty about the firm's performance in its line of business and the ROI that increase shareholders' wealth. This underpricing in response to public information is not an implication on the Benveniste and Spindt (1989) ${ }^{4}$ hypothesize that investors are being rewarded for disclosing private information they already possess. However, it can arise from costly information acquisition. This is consistent with Hanley (1993) who finds that the upward adjustment in offer price leads to higher IPO initial returns and that more underpricing (as well as probably more shares allocation) is needed to compensate investors who reveal inside information about IPO value during the book-building process.

Ritter (2003) further asserts that early pricing discussions focus on offer prices that are implied by the market values of publicly traded shares of comparable firms.

\footnotetext{
4 An elaboration of this point and a more complete discussion of the book-building process is provided in Lawrence Benveniste and William Wilhelm, "Initial Public Offerings: Going by the Book," Journal of Applied Corporate Finance 9 (Spring 1997).
}

While in consistent with Purnanandam and Swaminathan (2004) and Derrien (2005) has it that the offer prices reflect considerations of value relative to other publicly traded shares. Such that, share prices immediately after IPOs are too high compared to relative values, resulting in long-run under-performance. This is why Loughran and Ritter (2002) noted that any pattern of partial adjustment allocates risk between the issuer and the underwriter, and that investors who buy IPO shares also are parties to the allocation. Such investors are usually uninformed and so has little or no information about the firm's value. In consistent with firms and investors' need for information, Sherman (2005) states that, if investors' opportunity costs of information acquisition are correlated with market run-up, then public information can predict under-pricing and partial adjustment from the filing range to the offer price.

Although this assertion was argued against by different scholars when maximum and minimum of the filing range constrain the offer price, the range can be used to encourage investors to acquire information or to disclose their private information. Could this assertion be true? Lowry and Schwert (2004) re-iterated that even the mid-point of the filing range does not fully reflect public information. Such that, they question the authenticity of the implicit agreement between the underwriter and the issuer on the initial value and the limiting of adjustments of the range or the offer price in response to subsequent market movements.

According to the Nigerian SEC (2005), determining the right pricing of securities is very important to the success of an issue. For instance, if investors perceive an issue to be over-priced, many may not participate which could affect its success. On the other hand, if the issue is perceived to be under-priced, the issue may be overwhelmingly received while the issuer may feel "short changed". An underwriter, who over-prices securities may also be stuck with the securities for longer than desired or may in the alternative reduce the offering price of the securities which may consequently result in a loss to him while on the other hand, investors who buy under-valued (under-priced) securities are likely to earn higher returns in form of capital gains during the immediately post-issue period. Over or under-pricing of securities give the impression of professional ineptitude which could impact adversely on future patronage of the issuing house and indeed dampen issuer's desire to further access the capital market.

On the above note, Baron (1982) presents a model of under-pricing where issuers delegate the pricing decision to underwriters since investment bankers find it less costly to market IPO that is under-priced. However, Loughran and Ritter $(2002)^{5}$ instead emphasized the quid pro quos that underwriters receive from buy-side clients in return for allocating under-priced IPOs to them. The managers of

\footnotetext{
5 One can view issuers as seeking to maximize a weighted average of IPO proceeds, the proceeds from future sales (both insider sales and follow-on offerings), and side payments from underwriters to the people who will choose the Lead underwriter, Loughran and Ritter (2004), Financial Management, 5-37.
} 
issuing firms care less about under-pricing if they are simultaneously receiving good news about their personal wealth increasing.

One of the principal benefits of an efficient capital market is that it confers reliability on the information signals emitted by the market's security prices. For example, the ordinary investor may safely assume that the price provides a reliable signal of the security's semi-strong worth; the financial manager may assume that prices correctly signal the market's risk-return trade-off in relation to investment evaluation; the accountant may assume that the price movements in response to specific accounting data signal the utility of the data's informational content. ${ }^{6}$

In recent times, it has been shown that the informational signals given by security prices have even wider relevance as in Beaver, et al (1980) that security prices can be used to help predict future earnings. This assumption became the reverse of the former assertions that security price is a product of earnings predictions rather than a basis for predicting earnings. Information-based theories can explain partial adjustment relative to private information even in an environment where no party is motivated by a desire to allocate risk.

However, no hypothesis other than one based on intentional allocation of risk and expected return seems able to account for partial adjustment in response to public information that arrives before any information about the offer price is released to the market. ${ }^{7}$ Since consistency of offer prices with relative value can only hold on average, when compared to the first aftermarket price, some IPOs can be overpriced before the offer. Then if the pricing of over or under is materially based on public information from before the offering, then it should not be difficult for intended investors to spot those IPOs that have the tendencies to be overpriced and those that have likelihood of high yield initial returns. Regarding this concept, Benveniste and Spindt (1989) argue that, average underpricing serves multiple functions, including using allocations of underpriced shares to compensate investors for occasionally buying shares that are overpriced.

Benveniste and Spindt argument is consistent with the discovery of Sherman (2000) that, most offers are in form of repeated game where in exchange for access to future shares in high demand offerings, uninformed investors accept overpriced shares in low demand offerings. He further explained that, this is why in most cases underwriters try to limit the access to IPOs to only restricted and regular investors so that they can require them to occasionally

\footnotetext{
6 Semi-Strong Efficiency implies that the market absorbs all relevant published information from whatever source. But it does not follow that the corporate report is the principal or even an important source of information to the market. It is conceivable that the same information might previously be obtained by the market from other sources. Simon M. Keane, 1983:147, "Stock Market Efficiency: Theory, Evidence, Implications" Heritage Publishers

7 see the detail discussion on price formation literature in "public Information, IPO Formation, and Long-Run Returns: Japanese Evidence," Kutsuna, et al 2009, the Journal of Finance, LXIV (1) 505-546.
}

accept overpriced IPOs that lack adequate information. We refer to this as "a game of caricature in the IPOs trading' so that the firm is at a cross-road while the underwriters and the corporate executives of the firm are at the better. According to Bodie, et al (2007:97), ${ }^{8}$ the corporate executives reward underwriters with future investment banking businesses for underwriting the stocks with high asymmetric information.

Inadequate information on the performance of the intending firm going public is an abysmal sign of failure in the form of underpricing to underwriters at the IPO road shows which metamorphose into high volatile initial returns and lower long-term returns. The information need is very vital at the initial stage of IPOs pricing.

By this the IPOs price can be said to be underpriced, priced at par, or overpriced. Lowry et al (2010) confirmed that, there is considerable variation in the types of firms that go public. Some firms, according to them, are over 100 years old, are from well established industries, and are broadly covered in the media even before filing an IPO. In contrast, other firms are less than 1 year old, are from new industries that are not well understood by the market, and have received little or no media coverage prior to the IPO as such, the determination of the IPO price by the issuer and the underwriter tend to be more difficult and uncertain. This suggests that the greater amount of information available about more established firms should enable underwriters to more precisely estimate market demand for their shares, and therefore more accurately value the companies.

Ritter (1984), and Sherman and Titman (2002) observe that information asymmetry should also affect the precision of the price setting process. Specifically, it should be more difficult to estimate precisely the value of a firm characterized by high information asymmetry such that firms with higher uncertainty should have a higher volatility of initial returns. In line with the above assertion, Pastor and Veronesi (2005), and Pastor, et al (2009) observe that there is always a need to analyze the importance of market-wide uncertainty on firms' decisions to go public. Edelen and Kadlec (2005), and Lowry, et al (2010) find that market conditions also affect how aggressively issuers will price the offering and that variations in issuers' pricing behaviour in response to market conditions may also contribute to observed fluctuations in initial returns and/or the dispersion of initial returns over time. Solomon (2012) evidence that media coverage affects the price response to news announcements such that greater coverage of positive news stories raises investor expectations of future profitability, leading to price increases in the short-term and lower returns in the future around earnings announcements. He also suggests that investors rely on the media to help them process information and decide which stories are economically important. However, reflecting full information in the price of IPOs is only possible in efficient

\footnotetext{
8 For example, the firms have agreed to remove the link between analyst compensation and the amount of investment banking business they bring into the firm and to bar analyst from participating in IPO road shows.
} 
markets where apart from the internal efficiency, the external efficiency produce a situation where buyers and sellers will trade securities at prices reflecting a fair or equilibrium price, so that expected returns is commensurate with the security's risk (Machiraju, 2009). The investors in the capital market are the demand for the IPO stocks hence available and accessible information via prices produce the required demand for the IPOs.

\section{IPOs Price determination and the ATS on the Colombo Stock Exchange}

The ATS rules of the CSE (2012), provides that due to large price swings for a new issue, and in order to allow for large premiums on IPOs, price discovery is completely based upon the market rather than issue price which means that, under this circumstance, the issue price does not count too relevant but the market price at the issue. However, this market price is also determined electronically through the touchline (fair or equilibrium price) using the touchline bid and ask prices (a touchline bid is the highest bid price and the touchline ask is the lowest ask price in the market) available at that point in time. If bids or asks are unavailable for the day the touchline is defined as the previous closing price. For the first day of trading of an IPO the touchline is defined as the issue price (See CSE Automated Trading Rules, 2012, ATR). In this rule a hypothetical example is displayed for the determination of IPO market price during the auction on table 1 below:

Table 1. ATS IPO Price Determination

\begin{tabular}{ccc}
\hline Bid & Price & Ask \\
\hline & 100 & 100 \\
& 97 & 100 \\
& 95 & 300 \\
400 & $90^{*}$ & 200 \\
$100+200$ & $88^{*}$ & \\
$300+100$ & 87.5 & \\
\hline
\end{tabular}

Adapted from CSE ATR, 2012

The first touchline with asterisk 90 is the lowest ask price touchline at 200 units while the touchline with asterisk 88 is the highest bid price touchline of 400 units. At this point, the touchlines bid and ask prices are Rs.88 and Rs 90, respectively. However, to bridge variations, a pre-determined protection price is introduced at the discretion of the CSE to listed IPOs which is a percentage of ask or bid price touchlines added to the touchline ask or subtracted from the touchline bid, respectively. The protection price limits the possible price at which market orders can be executed. This relationship is determined as follows. For touchline bid protection price (i.e., for a sell market order), it is

$$
\mathrm{PPB}=\mathrm{TBP}-(\mathrm{TBP} * \text { Protection Rate })
$$

Where TBP is the touchline bid price.
For touchline asks protection price (i.e., a buy market order) is calculated as:

$$
\mathrm{PPA}=\mathrm{TAP}+(\mathrm{TAP} * \text { Protection Rate })
$$

Where TAP is the touchline ask price.

So that the actual touchline bid protection price $(\mathrm{PPB})$ as in Table 1 will be Rs 88 -(Rs $\left.88^{*} .1\right)=$ Rs 80 . That is, if the CSE decide the protection rate as $10 \%$. Likewise the touchline ask protection price (PPA) will also be Rs $90+(\mathrm{Rs}$ $90 * .1)=$ Rs 99 given the same $10 \%$ protection rate. At this point, if for instance a broker places an order for let's say 800 units IPO stocks of company $\mathrm{X}$ at the current ask protection price of Rs 99, the Table 1 will be translated into a book record as table 2

The Broker's market order would thus be executed electronically as follows: 200 IPOs units at Rs 90 of A; 300 IPO units at Rs 95 of B and 100 IPO units at Rs 97 of Y while the balance of 200 units that could not be matched will be automatically cancelled since the 100 units available for $\mathrm{Z}$ is above the ask protection price. By this ATS illustration for IPOs price determination, we examine the possibility of price fully reflecting all relevant information to meet the Random Walk Hypothesis (RWH) assumption which is a major conditionality for the efficient market literature.

Table 2. ATS Order Determination.

\begin{tabular}{cccc}
\hline Price makers & Price & \multicolumn{3}{c}{ Ask } \\
\hline & & Orders & Broker \\
Protection & 100 & 100 & $\mathrm{Z}$ \\
Rs99 (bid) & & & \\
& 97 & 100 & Y \\
& 95 & 300 & B \\
Touchline 90 & 90 & 200 & A \\
(ask) & & & \\
Touchline 88 & & & \\
(bid) & & & \\
\hline
\end{tabular}

Adapted from the CSE ATR, 2012

\section{Model Specification and Data Description}

We drew the offering prices and closing market prices of IPO stocks trading companies in the CSE index after 1997. Specifically, monthly prices from 2000-2012 of IPO stocks trading after the introduction of the ATS is observed to identify the growth and level of efficiency of the market after the ATS in determining the IPO prices which according to the EMH, should be able to "fully reflect" all information on the stock. We utilize the monthly open and close prices from the selected IPOs and fully access the data from the CSE data base. About 231 IPO equity stocks were involved for monthly trading which amounts to 35,979 observations.

The modelling is traced from the expected return or the "fair game" models which describe the conditions upon which relevant information and the equilibrium expected return on a security is made as a function of its risk 
expressed as:

$$
\mathrm{E}\left(\mathrm{P}_{\mathrm{j}, \mathrm{t}+1} / \Phi_{\mathrm{t}}\right)=\left[1+\mathrm{E}\left(\mathrm{R}_{\mathrm{j}, \mathrm{t}+1} / \Phi_{\mathrm{t}}\right)\right] \mathrm{P}_{\mathrm{jt}}
$$

Here, $\mathrm{E}$ is the expected value operator; $\mathrm{E}\left(\mathrm{R}_{\mathrm{j} . \mathrm{t}+1} / \Phi_{\mathrm{t}}\right)$ is the equilibrium expected return projected on the information availability $\left(\Phi_{\mathrm{t}}\right) ; \quad \mathrm{P}_{\mathrm{jt}}$ is the price of security $\mathrm{j}$ at time $\mathrm{t} ; \mathrm{P}_{\mathrm{j}, \mathrm{t}+1}$ is the price of stock $j$ at $t+1 ; R_{j, t+1}$ is the percentage return for one period expressed as $P_{j, t+1}-P_{j t} / P_{j t}$ ). It must be noted that the random variables in equation (1) are $\mathrm{P}_{\mathrm{j}, t+1}$ and $\mathrm{R}_{\mathrm{j}, t+1}$. The conditional expected notation of the "fair game" model expressed above implies that whatever the model assumed to apply, the information in $\Phi_{t}$ is fully utilized in determining equilibrium expected returns, such that the $\Phi_{t}$ is "fully reflected" in the formation of the price $\mathrm{P}_{\mathrm{jt}}$ (Fama, 1970). However, by extension, the sub-martingale model assumes that $\mathrm{E}\left(\mathrm{P}_{\mathrm{j}, t+1} / \Phi_{\mathrm{t}}\right) \geq$ Pjt and $\mathrm{E}\left(\mathrm{R}_{\mathrm{j}, t+1} / \Phi_{\mathrm{t}}\right) \geq 0$ believing that if these conditions are absolutely met, then the price sequence $P_{j t}$ for security $j$ follows a sub-martingale with respect to information sequence $\Phi_{\mathrm{t}}$ which means according to Fama (1970), the expected value of the next period's price, as projected on the basis of the information $\Phi_{t}$, is equal to or greater than the current price, however, if the assumption holds on equality (i.e., expected returns and price changes are zero), then the price sequence follows the martingale assumption.

Looking at the Random Walk Hypothesis (RWH), we understand that efficient markets are suggested at instances where successive price changes (or successive one-period returns) are independent and the successive changes (returns) are identically distributed. Such scenario indicates that the current price of the security "fully reflects" available information modelled as

$$
\mathrm{f}\left(\mathrm{R}_{\mathrm{j}, \mathrm{t}+1} / \Phi_{\mathrm{t}}\right)=\mathrm{f}\left(\mathrm{R}_{\mathrm{j}, \mathrm{t}+1}\right)
$$

An indication that the conditional and marginal probability distributions of independent random variables are identical and the $f$ density function must be the same at every given $t$. The most important assumption here to note is that, under the RWH, the entire distribution is independent of the available information $\Phi_{t}$. But that does not discredit and misconstrue the idea of the RWH; instead the model is saying that the sequence (the order) of the past returns is of no consequence in assessing distributions of future returns (Fama, 1970). Upon this assumption, the EMH express the "fully reflected" information in the price of the stock to describe efficient stocks market. We use stationary test, normality test, correlation test, and also employ the EGARCH and TGARCH to determine the rate of information asymmetry deterring the market efficiency despite the ATS fair price determination. EGARCH and the TGARCH came on board to capture the asymmetric shocks to the conditional variance. Nelson (1991) Exponential GARCH takes the form of natural logarithm of the conditional variance so that it is allowed to vary over time as a function of the lagged error terms rather than the lagged squared errors. The EGARCH $(1,1)$ is written as:

$$
\operatorname{Inh}_{\mathrm{t}}^{2}=\omega+\alpha\left|\varepsilon_{\mathrm{t}-1} / \mathrm{h}_{\mathrm{t}-1}\right|+\gamma\left(\varepsilon_{\mathrm{t}-1} / \mathrm{h}_{\mathrm{t}-1}\right)+\beta \operatorname{Inh}_{\mathrm{t}-1}^{2}
$$

The y captures the asymmetric effect so that the conditional variance is always positive even if the parameter values are negative. Furthermore the Threshold GARCH of Glosten, et al (1993) modifies the original GARCH specifications using a dummy variable with the assumption that unexpected changes in the market returns have different effects on the conditional variance of the returns. Such that good news goes with an unforeseen increase contributing to the variance through the coefficient $\beta$ instead of an unexpected decrease which is presented as a bad news and contributes to the variance with the coefficient $\alpha+y$, so that, if $y>0$, the leverage effect exist and news impact is asymmetric if $\mathrm{y} \neq 0$ (Magnus \& Fosu, 2006). The TGARCH is,

$$
\mathrm{h}_{\mathrm{t}}=\omega+\alpha \varepsilon_{\mathrm{t}-1}^{2}+\gamma \varepsilon_{\mathrm{t}-1}^{2} \zeta_{\mathrm{t}-1}+\beta \mathrm{h}_{\mathrm{t}-1}
$$

It is obvious to not that the IPO stocks performance have consistently undergone series of studies to determine the ex ante and post ante returns yet, the volatility persist with the market inefficiency and locks in the stock market. We tested for the unit root using the ADF and observed that the closing price and the lagged closing price are $\mathrm{I}(0)$ variables as shown on table 3 below.

Table 3. Unit Root Test for closing Price and lagged of closing price.

\begin{tabular}{ccc}
\hline Method & Statistic & Prob.** \\
\hline ADF - Fisher Chi-square & 363.754 & 0.0000 \\
ADF - Choi Z-stat & -18.7010 & 0.0000 \\
\hline
\end{tabular}

** Probabilities for Fisher tests are computed using an asymptotic Chi-square distribution. All other tests assume asymptotic normality. Total number of observations: 71885 Cross-sections included: 2 .

Table 4. Heteroskedasticity Test: $A$ RCH

\begin{tabular}{lcll}
\hline F-Statistic & 0.000249 & Prob.F(1.35975) & 0.9874 \\
Obs*R Squared & 0.000249 & ProbChi-Square(1) & 0.9874 \\
\hline \multicolumn{4}{c}{ Table 5. Heteroskedasticity Test: White } \\
\hline F-Statistic & 0.39654 & Prob. F(2,35975) & 0.9611 \\
Obs*R-Squared & 0.079315 & ProbChi-Square(1) & 0.9611 \\
\hline
\end{tabular}

\section{Result and Discussions}

The conditions for the RWH are demonstrated in this empirical analysis tested on price independence of IPO stocks, that is $\mu_{\mathrm{t}} \neq \mu_{\mathrm{t}-1}$ where $\mathrm{p}>0$; so that the series are non-stochastic to satisfy at least the weak EMH. In our analysis it is revealed that the quantile-quantile test graph indicating non-normality because of the series deviation from the mean line of normal distribution indicating the stochastic nature of the IPOs prices. With this trend, the data also exhibit robust correlation and autocorrelation reported by the large values of the Q-statistics. These values, because of their correlation strength have shown very strong correlation strength significance reported by the P-values of zeros; which predicates that the series are 
strongly auto-correlated and serially correlated thereby disproving the RWH propositions and the EMH satisfaction. However, we observed that the variables are not Heteroskedastic as proven by the Arch and White tests in tables 4 and 5 respectively.

Descriptive Statistics report that the series are not normally distributed given the $\mu>0$ and a median of -0.1188 indicating a series with a long upper tail) and large standard deviation value of $95 \%$. Furthermore, the distribution is highly positively skewed (value greater than 0, i.e., 47.252) showing a high information asymmetry. Since the kurtosis of 4068.967 is far greater than 3 (i.e., normal tails) it indicates a distribution with high peak (leptokurtic distribution). The JB-stat also is robust and shows very high non-normality significance with $\mathrm{p}=0$ (i.e., in thousands).

With these evidences glaring, we ascertain the information asymmetry condition of the CSE IPO stock prices. The EGARCH and TGARCH report almost similar trend. For instance, both models report that the series exhibit some substantial degree of correlation as reported by the D-W's 1.65 and 1.79 respectively. These values are indicating positive serial correlation since each of them is substantially less than 2 which shouldn't be so under a condition of market efficiency. Stylised facts are also eminent in this market. In the EGARCH and TGARCH results, we observe that volatility is highly robust such that, volatility clustering $\alpha+\beta \geq 1$ could be seen to be 1.5016 and 1.5443 respectively. This means that the shocks of the lagged price displays a persistence for longer periods before they die out as supported by the GARCH of conditional variance, conditional standard deviation, and residual values The prices of IPOs in the market also exhibit some leverage effects (information asymmetry). The EGARCH reports information asymmetry of -0.0041 but tend to indicate that both good and bad news have almost equal impact on the IPO price $(\alpha+\gamma<\alpha$ i.e. $0.5394<0.5435$ instead of being greater than alpha). In the same vein, the TGARCH also reports $-0.0285<0.8485$ with similar characteristics that good and bad news shocks are indifferent of each other. However, the two models report that the distribution is leptokurtic, meaning that it is peaked and fat-tailed given the $\mathrm{D}-\mathrm{W}$ values of 1.65 and 1.79 , respectively.

These observations means that the market price for IPO stocks in the CSE exhibit double-edge equal-shock from both good and bad news and that information imbalance is very eminent in the market despite the ATS and because shocks tend to persist over a very long period of time, and prices are correlated and interdependent and therefore the market fails to satisfy the condition of EMH of Fama (1970).

The information imbalance is evident by proving that information accumulates when financial markets are closed is reflected in prices after the market reopen; such that volatility may seem high for IPO stocks because information about their true value may be locked-in to the parties especially the issuer and the underwriter. It is also note worthy to assert that, the information discrepancies as a result of favourable market conditions in some cases contribute to the robustness of information asymmetry because of the issuers and insiders singular knowledge of the firm and the market above other investors which is in congruence with Ritter (1984), and Sherman and Titman (2002) observe that information asymmetry should also affect the precision of the price-setting process such that difficulty is eminent in estimating precisely the value of a firm characterize by high information asymmetry with higher volatility of initial returns. Consistent also with this outcome, are Pastor and Veronesi (2005), Pastor, et al (2009), Edelen and Kadlec (2005), and Lowry, et al (2010) that there is always a need to analyze the importance of market-wide uncertainty on firms' decisions to go public in that market conditions affect how aggressively issuers will price the offering and that variations in issuers' pricing behaviour in response to market conditions may also contribute to observed fluctuations in initial returns and/or the dispersion of initial returns over time. This therefore tends to report the consistency of this result with Rubalcava (2013) that base argument of mispricing to most likely competitive reasons and Lo (2007) argument to replace the EMH with adaptive Market hypothesis that, at some spaces within time, investors try to adapt to the changing and highly competitive new environment who in some instances, make mistakes or act irrationally, thereby result to volatile assets prices.

\section{Conclusion}

We find that the performance of the Colombo Stock Exchange (CSE) for IPOs does not exhibit market efficiency in and the price of IPOs are not independent and so auto-correlate and does not follow the RWH to satisfy for a weak efficient market. It is further acknowledged that the price determination of IPOs via the ATS still fall short of reflecting "full" information and so tend to vary negatively or positively with every available good or bad news. The news effect in the market is sacrosanct in nature such that investors respond to both good and bad news in almost equal proportion and as such renders the short-run shocks almost persistent over a very long period of time.

Does this therefore, inform us that the EMH really is not realistic in the growing and complex financial market as postulated by Shiller (2002) and Lo (2013) and other behavioural finance theorists? The more questions on this market efficiency keeps erupting as more and more historical data on the stock market is employed because they always fail the common test for efficiency even with the great development in automation that almost signal information referencing and sharing. Therefore we still ask, when and how will the capital market be efficient?

\section{References}

[1] Baillie, R.T., and Bollerslev, T. (1991) Intra Day and Inter Day Volatility in Foreign Exchange rates, Review of Economic Studies 58, 565-585. 
[2] Baron, D. (1982) A Model of the Demand for Investment Banking Advising and Distribution Services for New Issues, Journal of Finance 37, 955-976.

[3] Bartram, S. M., Brown, G., and Stulz, R. M.,(2012) Why are U.S Stocks More Volatile? Journal of Finance LXVII, (4), $1329-1370$

[4] Beaver, W., Lambert, R. and Morse, D. (1980) the Information Content of Security Prices, Journal of Accounting and Economics, March

[5] Benveniste, L.M., and Spindt, P.A., (1989) How investment Bankers Determine the Offer Price and Allocation of New Issues, Journal of Financial Economics 24, 343-362.

[6] Benveniste, L.M., and Wilhelm, W.J., (1990) A Comparative Analysis of IPO Proceeds under Alternative Regulatory Environments, Journal of Financial Economics 28, 173-207.

[7] Bessembinder, H., Chan, K., and Seguin, P.J., (1996) An Empirical Examination of Information, Differences of Opinion, and Trading Activity, Journal of Financial Economics 40,105-134.464 The Journal of Finance.

[8] Bodie, Z., Kane, A., Marcus, A. J., and Mohanty, P (2005) Investments, $6^{\text {th }}$ edition, Tata McGraw-Hill Publishing Company, New Delhi.

[9] Bollerslev, T., Engle, R.F., and Nelson, D.B., (1994) ARCH Models, in: Handbook of Econometrics, Edited by R.F. Engle and D.L. Mcfadden, Elsevier Science, 2959-3037.

[10] Bradley, D.J., and Jordan, B.D., (2002) Partial Adjustment to Public Information and IPO Underpricing, Journal of Financial and Quantitative Analysis 37, 595-616.

[11] Cheung, C.S. and Krinsky, I., (1994) Information Asymmetry and the Underpricing of Initial Public Offerings: Further Empirical Evidence, Journal of Business Finance and Accounting, 21 (5), 739-747.

[12] Cornell, B. (1978) Using the Options Pricing Model to Measure the Uncertainty Producing Effect of Major Announcements, Financial Management 7, 54-59.

[13] CSE Automated Trading Rules, 2012, www.cse.lk.

[14] Derrien, F., (2005) IPO Pricing in "Hot" Market Conditions: Who leaves Money on the Table? Journal of Finance 60, 487-521.

[15] Edelen, R.M., and Kadlec, G.B., (2005) Issuer Surplus and the Partial Adjustment of IPO Prices to Public Information, Journal of Financial Economics 77, 347-373.

[16] Fama, E. F., (1965) the Behaviour of Stock Market Prices, Journal of Business 38 (1), 34-105.

[17] Fama, E. F., (1968) Risk, Return and Equilibrium, Report No.6831, University of Chicago, Centre for Mathematical Studies in Business and Economics, June.

[18] Fama, E. F , (1970) Efficient Capital Markets: A Review of Theory and Empirical Work, Journal of Finance 25, 383-417.

[19] Gerity, M.S., and Mulherin, J.H. (1992) Trading Halts and Market Activity: An Analysis of Volume at the Open and Close, Journal of Finance 47, 1765-1784.

[20] Glosten, L.R., Jagannathan, R., and Runkle, D., (1993) On the Relation between the Expected Value and the Volatility of the Nominal Excess Return on Stocks, Journal of Finance 48, 1779-1801.

[21] Hanley, K. W., (1993) the Under-pricing of Initial Public Offerings and the Partial Adjustment Phenomenon, Journal of Financial Economics 34, 231-250.

[22] Harris, L. (1986) A transaction Data Study of Weekly and Intra-daily Patterns in Stock Returns, Journal of Financial Economics 16, 99-117.

[23] Harvey, C.R., and Huang, R.D. (1991) Volatility in the Foreign Currency Futures Market, Review of Financial Studies 4, 543-569.

[24] Harvey, C.R ., and Huang, R.D. (1992) Information Trading and Fixed Income Volatility, Unpublished Manuscript, Department of Finance, Duke University.

[25] Islam, Md.A., Ali, R., and Ahmad, Z., (2010) An Empirical Investigation of the Underpricing of Initial Public Offerings in the Chittagong Stock Exchange, International Journal of Economics and Finance 2 (4), 36-46.

[26] Jensen, M., (1968) the Performance of Mutual Funds in the Period 145-64, Journal of Finance 23, 389-416.

[27] Jensen, M ., (1969) Risk, the Pricing of Capital Assets, and the Evaluation of Investment Portfolios, Journal of Business $42,167-247$.

[28] Lintner, J., (1965) The Valuation of Risk Assets and the Selection of Risky Investments in Stock portfolios and Capital Budgets, Review of Economics and Statistics, XLVII, 13-37.

[29] Lo, A.W. (2007) Efficient Market Hypothesis, in L. Blume and S. Durlauf, the New Palgrave: A Dictionary of Economics, Second Edition, 2007. New York: Palgrave McMillan.

[30] Loughran, T., and Ritter, J.R., (2002) Why don't Issuers Get Upset About Leaving Money on the Table in IPOs? Review of Financial Studies 15, 413-443.

[31] Loughran, T., and Ritter, J.R., (2004) why has IPO Underpricing Changed Over Time? Financial Management $33,5-37$.

[32] Lowry, M., Officer, M.S., and Schwert, G.W., (2010) the Variability of IPO Initial Returns, Journal of Finance LXV (2), 425-465.

[33] Lowry, M., and Schwert, G.W., (2004) is the IPO pricing process efficient? Journal of Financial, Economics 71, 3-26.

[34] Machiraju, H.R., (2009) The Working of Stock Exchanges in India, $3^{\text {rd }}$ edition, New Age International Publishers, New Delhi.

[35] Magnus, F.J., and Fosu, O-T.E., (2006) Modelling and Forecasting Volatility of Returns on the Ghana Stock Exchange Using GARCH Models, American Journal of Applied Sciences 3 (10), 2042-2048.

[36] Murray, J.E. (2008) Identifying, Separating, and Managing Asymmetric Information in Early 20c Health Insurance, http://www.gmu.edu/departments/economics/pboettke/works hop/spring08/Identifying\%20and\%20managing\%20draft\%2 oJanuary\%202008.pdf.

[37] Myers, S.C., and Majluf, N.S., (1984) Corporate Financing 
and Investment Decisions When Firms have Information that Investors do not have, Journal of Financial Economics 13, 187-221.

[38] Nelson, D.B., (1991) Conditional Heteroskedasticity in Asset Returns: A New Approach, Econometrica 59, 347-370.

[39] Niederhoffer, V., and Osborne, M.F.M., (1966) Market Making and Reversal on the Stock Exchange, Journal of the American Statistical Association 61, 897-916.

[40] Oluba, M., (2008) Nigeria: The Equity Market Crisis, Causes, and Solutions. Retrieved from: http://allafrica.com/stories/200811040483.html

[41] Pastor, L., and Veronesi, P., (2005) Rational IPO Waves, Journal of Finance 60, 1713-1757.

[42] Pastor, L., Taylor, L.A., and Veronesi, P., (2009) Entrepreneurial Learning, the IPO Decision, and the Post-IPO Drop in Firm Profitability, Review of Financial Studies 22, 3005-3046.

[43] Purnanandam, A., Swaminathan, B., (2004) Are IPOs really underpriced? Review of Financial Studies 17, 811-848.

[44] Ritter, J.R., (1984a) the "Hot Issue" Market of 1980, Journal of Business 57, 215-240.

[45] Ritter, J.R., (1984b) Signalling and the Valuation of Unseasoned New Issues: A Comment, Journal of Finance 39, $1231-1237$.

[46] Ritter, J.R., (2003), Investment Banking and Securities Issuance, in: G.M. Constantinides, M. Harris, and R. Stulz (eds.), Handbook of the Economics of Finance, North Holland.

[47] Rock, K., (1986) Why New Issues are Under-Priced, Journal of Financial Economics 15, 187-212.
[48] Roll, R., (1968) The Efficient Market Model Applied to U.S. Treasury Bill Rates, Unpublished PhD Thesis, Graduate School of Business, University of Chicago.

[49] Rubalcava, A. (2013) Are Financial Markets Efficient? Journal of Business and Financial Affairs 2(2), http://dx.doi.org/10.4172/2167-0234.1000e136.

[50] Shiller, R.J. (2002) From Efficient Market Hypothesis to Behavioural Finance, Cowles Foundation Discussion Paper No. 1385, http://papers.ssrn.com/abstract_id=349660.

[51] Scholes, M., (1969) A test of the Competitive Hypothesis: The Market for New Issues and Secondary Offerings, Unpublished PhD Thesis, Graduate School of Business, University of Chicago.

[52] Securities and Exchange Commission Rules and Regulations (SECRR) as amended 2001, 2002, 2003, 2005, 2006, 2008, 2009, 2010, 2011 and 2012, Nigeria, WWW.sec.ng.org

[53] SEC (2005) Public Offering and Sale of Securities, Securities and Exchange Commission Publication, Nigeria.

[54] Sherman, A., and Titman, S., (2002) Building the IPO Order Book: Underpricing and Participation Limits with Costly Information, Journal of Financial Economics 65, 3-29.

[55] Solomon, D.H., (2012) Selective Publicity and Stock Prices, Journal of Finance LXVII (2), 599-637.

[56] Spatt, C., and Srivastava, S. (1991). Pre-play Communication, Participation Restrictions, and Efficiency in Initial Public Offerings, Carnegie-Mellon University, Graduate School of Industrial Administration, Reprint NO. 1415.

[57] Wang, T.Y., Winton, A., and Yu, X (2010) Corporate Fraud and Business Conditions: Evidence from IPOs, Journal of Finance vol. IXV, No. 6, December. 